\title{
Sobre la deseable relación entre comprensión pública de la ciencia y alfabetización científica
}

Resumen: Parece conveniente una mayor colaboración entre la línea de trabajo de comprensión pública de la Ciencia y la de alfabetización científica. La comprensión pública de la Ciencia, orientándose hacia una visión mucho más amplia y participativa de la ciudadanía como agente y sujeto activo en el papel desempeñado por la Ciencia en la sociedad. La alfabetización científica, haciendo progresar la educación científica desde estar orientada básicamente a formar futuros titulados universitarios científicos e tecnólogos, a que al menos la enseñanza obligatoria se centre en la formación científica básica de la ciudadanía, para que sea útil en la vida actual y futura del conjunto de la población.

Palabras clave: comprensión pública de la Ciencia, alfabetización científica.

\author{
Pedro Membiela* \\ Artículo recibido: 30-8-2007 y aprobado: 12-10-2007 \\ Pedro Membiela \\ Articulo recibido: 30-8-2007 y aprobado: 12-10-2007

\begin{abstract}
About desirable relation between public understanding of science and scientific literacy
\end{abstract}

Abstract: It seems convenient a bigger collaboration between public understanding of Science and scientific literacy. The public understanding of the Science, being guided toward a vision much wider and more participant of the citizenship like agent and active fellow in the paper to play for the Science in the society. The scientific literacy, making progress the scientific education from being guided basically to form futures titled scientific university students and technologists to that at least the obligatory teaching is centered in the basic scientific formation of the citizenship, so that it is useful in the current and future life of the population's group.

Keywords: public understanding of science, scientific literacy.

\footnotetext{
* Universidad de Vigo.
} 


\section{Introducción}

Es un hecho relativamente habitual que exista escasa conexión entre campos relativamente próximos, e incluso dentro del mismo, como es el caso del conocimiento e investigación sobre la enseñanza de las ciencias generados desde ámbitos profesionales diferentes. Así, existe escasa conexión entre las comunidades profesionales de profesores de ciencias, organizadas habitualmente por niveles (secundaria, universidad) e incluso por ámbitos (Biología, Física, Química, Geología), y las centradas en la investigación en enseñanza de las ciencias, denominadas en nuestro entorno de didáctica de las ciencias experimentales.

Esta falta de conexión no debe extrañarnos, pues son las comunidades en la práctica quienes determinan los intereses y temáticas preferentes, y de esta manera campos de conocimiento muy próximos pueden estar poco relacionados. Esto explica cómo existen líneas de trabajo muy poco conectadas, como es el caso de las que se ocupan de la divulgación de la Ciencia y de la enseñanza de las ciencias. La divulgación de la Ciencia es un ámbito centrado en el periodismo científico, los museos de Ciencia y lo que se ha denominado Comprensión pública de la Ciencia, y la didáctica de las ciencias experimentales se ocupa fundamentalmente de la Educación en Ciencias en el ámbito escolar. No obstante, existen puntos de encuentro desde la perspectiva teórica y en la práctica, y se podría mencionar su mutuo interés en los museos de la ciencia.

Sin embargo, hay otro posible nexo de unión que ha recibido poca atención: la relación entre lo que se ha llamado
Comprensión pública de la Ciencia y la alfabetización científica, línea de formación en ciencias para toda la ciudadanía que ha recibido gran atención desde hace algún tiempo en la didáctica de las ciencias experimentales. Ambas están centradas en la formación científica del conjunto de la población: una para conocer cuál es la formación que tiene el conjunto de la ciudadanía y otra desde la perspectiva de cuál debería ser la formación básica en ciencias a conseguir desde la escuela. Cómo veremos hay dentro de estas dos líneas de trabajo muy diversos enfoques y en todo caso queda pendiente cómo conectar un campo con el otro, lo que probablemente redundará en beneficio mutuo.

\section{La comprensión pública de la ciencia}

Esta cuestión consiguió actualidad gracias a los trabajos de investigación que midieron actitudes y comprensión de la Ciencia por el gran público (y es significativo que se hable de público y no de ciudadanos, por ejemplo), mediante cuestionarios a gran escala realizados en diversos países. Sus principales conclusiones tuvieron un gran eco social, como aquella que señalaba al 90\% de la población estadounidense y británica como analfabeta científica. Sin embargo, este tipo de trabajos ha recibido diversas críticas (Wyne, 1995), como que no tienen en cuenta el contexto social, o que tienden a cargar las culpas de los problemas existentes en la ciudadanía y de esta manera exoneran de sus responsabilidades a la Ciencia, a sus instituciones y a la propia cultura científica.

Hoy en día se entiende que se debe superar el modelo dominante de investigación y acción en este campo, limitado 
a problematizar las capacidades y procedimientos de los ciudadanos en relación con la Ciencia, y abrirse a modelos más complejos centrados en conocer en profundidad como la gente vive y usa la Ciencia en su contexto personal y social. La Ciencia en la sociedad se considera una construcción social más, resultado de la actuación de los diferentes individuos y grupos sociales en diversos contextos cotidianos donde se forman verdaderas comunidades científicas en la práctica, cuyo funcionamiento no se puede explicar o reducir a la suma de actuaciones de sus integrantes individuales. Esto es lo que supone de facto la línea de investigación centrada en las grandes encuestas asociada a un modelo de déficit que fundamentalmente considera ignorante al conjunto de la población.

Sin embargo, existen otras perspectivas centradas en cómo funciona la Ciencia en la práctica que realizan habitualmente investigaciones de corte etnográfico, realizadas en profundidad y a pequeña escala (Layton et ál., 1993), y que obtienen conclusiones como que las mujeres obreras rechazan la concepción dominante entre los médicos de que la menstruación es una reproducción fallida, entendiéndola más bien como el proceso que las hace mujeres o que la respuesta de los ciudadanos ante la Ciencia y la Tecnología en situaciones de riesgo, depende más de su experiencia o de la percepción de instituciones y actores sociales relevantes que de las cualidades de la propia información científica y tecnológica suministrada, y pueden considerar este conocimiento como irrelevante a pesar de que los expertos opinen lo contrario, entre otras razones porque muchas veces carecen de la libertad social o del poder que tienen los propios científicos.

Otro aporte importante de estos enfoques es considerar la ignorancia como una construcción social positiva, superando la concepción de la ignorancia como vacío o falta de conocimiento; así, se menciona el caso de los trabajadores de una planta nuclear de reprocesamiento que incluso llegaban a justificar su ignorancia por razones de ahorro de tiempo, de reducción de incertidumbre y sobre todo por la presencia de expertos de seguridad de la propia empresa que suponían tenían un conocimiento profundo de la Ciencia y la Tecnología implicada en esos riesgos.

También se habla de que la verdad científica está condicionada, como el caso de los granjeros que vivían cerca de la misma planta de reprocesamiento, que en principio se mostraban escépticos sobre que el accidente de Chernobil fuera la causa de la contaminación radioactiva que padecían, tal como afirmaban los científicos, para más tarde mostrarse ambivalentes, según los investigadores, probablemente porque muchas familias de la zona dependían de la planta nuclear como fuente de trabajo.

Otra importante conclusión de un trabajo realizado sobre la utilización del conocimiento científico por las personas mayores para usar su calefacción doméstica, del suministrado por los médicos a los padres con niños con Síndrome de Down o en el caso de la planta de reprocesamiento nuclear, es que la información recibida fue de muy poca utilidad, básicamente por su carácter genérico o, lo que es lo mismo, que la información 
científica para ser útil necesita adaptarse al contexto en que va a ser usada.

Algunas cuestiones que hoy se plantean desde estas perspectivas son profundizar en cómo funciona la Ciencia en la práctica y las relaciones entre comprensión e interés, más allá del modelo que atribuye los problemas de desinterés, falta de apreciación o incluso de rechazo de los ciudadanos, exclusiva o fundamentalmente, a la falta de una correcta comprensión y conocimiento, o que la apatía, la hostilidad o las conductas ambivalentes en relación con la Ciencia y la Tecnología son debidas al desconocimiento de sus principios de racionalidad.

En tal sentido, una de las cuestiones básicas es hacer propuestas sobre la formación científica básica de los ciudadanos, lo que se ha llamado alfabetización científica y tecnológica, que incluye el papel que los ciudadanos deben jugar en la toma de decisiones de la sociedad democrática en relación con la Ciencia y la Tecnología. En este campo es fundamental la acción educativa, y no debemos olvidar que la escuela es, entre otras cosas, la más importante institución formadora social.

\section{La alfabetización científica}

En la década de los ochenta se ha producido en el mundo anglosajón una crisis en la enseñanza de las ciencias denominada de la alfabetización científica (Matthews, 1994), que tiene relación con las deficiencias encontradas en los estudios sobre Comprensión pública de la Ciencia realizados sobre el conjunto de la población.

La alfabetización científica engloba muy diversos comportamientos, cono- cimientos, habilidades intelectuales y predisposiciones (Champagne y Lovitts, 1989) que varían según la opinión de los diferentes autores. Así, para algunos una persona científicamente alfabetizada es aquella capaz de aplicar adecuadamente el conocimiento científico, la resolución de problemas, y la toma de decisiones a los asuntos personales, cívicos y profesionales. Para otros, significa la habilidad y la inclinación para continuar aprendiendo Ciencia a lo largo de toda la vida. Según otros, equivale a tener conocimientos acerca de la Ciencia y unas determinadas habilidades intelectuales, sean usadas o no. Hodson (1992) señala la importancia de la alfabetización científica crítica, a través de la promoción del pensamiento crítico y las destrezas de las tomas de decisiones, y que está ligada a la alfabetización política y la ideología de la Educación como reconstrucción social. Para Champagne y Lovitts (1989) existe una alfabetización científica orientada a la vida diaria y una escolar, centrada en el conocimiento y las habilidades intelectuales.

Precisamente asociada a la alfabetización científica se encuentra la necesidad de un currículo básico y común para todos, como uno de los mecanismos básicos de la pretendida igualdad de oportunidades y que a ningún estudiante se le debería enseñar un currículo alternativo por razones de raza, sexo, orígenes sociales o conocimientos intelectuales.

Uno de los ejemplos más conocidos de alfabetización científica es el Proyecto 2001 de la AAAS (1993), que promueve la alfabetización de todos los estudiantes en Ciencias, Matemáticas y Tecnología 
para ayudar a los ciudadanos a tener una vida interesante, responsable y productiva, y define una persona alfabetizada científicamente como aquella consciente de que la Ciencia, las Matemáticas y la Tecnología son empresas humanas interdependientes, con potencialidades y limitaciones, que comprenden conceptos clave y principios de la Ciencia, que está familiarizada con el mundo natural y reconoce su diversidad y unidad, y usa el conocimiento científico y las maneras científicas de pensar para fines individuales y colectivos (Rutherford y Ahlgren, 1990). La alfabetización científica ha sido considerada como un objetivo clave en la reforma educativa estadounidense, donde se define como el conocimiento y comprensión de los conceptos científicos y de los procesos necesarios para la participación en los asuntos ciudadanos y culturales, la productividad económica y la toma de decisiones.

Se han producido críticas a la idea de considerar como objetivo central de la educación científica la alfabetización científica, así lo considera Fourez (1989) que sólo se centran en el individuo, olvidando la dimensión colectiva y conflictiva de la vida humana. Otros (Kyle, 1995) opinan, quizás de forma abusiva, que el desarrollo de la alfabetización científica fue el objetivo de las reformas educativas de los últimos cincuenta años, sin que hubieran tenido mucho éxito en trascender desde la alfabetización científica escolar a la adulta.

\section{A modo de conclusión}

Debe haber un encuentro entre dos tendencias con orígenes diferentes pero convergentes: por un lado la denominada Comprensión pública de la Ciencia y por otro la educación científica para el conjunto de la población, también llamada alfabetización científica.

Por un lado, se debe progresar desde el modelo de déficit que simplemente considera ignorante al conjunto de la población y le confiere sólo el papel pasivo de mejorar su comprensión de la Ciencia, y progresar hacia una visión mucho más amplia y participativa que considere a la ciudadanía agente y sujeto activo, en primer lugar en la definición del papel desempeñado por la Ciencia en la sociedad.

Por otro lado, el sistema educativo también debe progresar desde la concepción dominante de una educación científica orientada básicamente a formar futuros titulados universitarios como científicos y tecnólogos, hacía que al menos la enseñanza obligatoria se centre en la formación científica básica de la ciudadanía, en la alfabetización científica, lo que supone orientar la enseñanza de las ciencias para que sea útil en la vida actual y futura del conjunto de la población, y no que sólo tenga sentido dentro de la propia institución escolar.

Parece claro que una mayor colaboración entre la línea de trabajo de comprensión pública de la Ciencia y la de alfabetización científica puede generar mutuos beneficios. $\boldsymbol{\Delta}$ 


\section{Referencias}

AAAS (1993). Benchmarks for Scientific Literacy. Washington: Oxford University Press.

Champagne, A.B. y Lovitts, B.E. (1989). Scientific literacy: A Concept in Search of Definition. En Champagne, A.B.; Lovitts, B.E. y Calinger, B.J. Scientific Literacy. Washington: AAAS.

Fourez, G. (1989). Scientific literacy, Societal Choices and ideologies pp. 89-108 en Champagne, A. B.; Lovitts, B. E. y Calinger, B. J. Scientific Literacy. Washington: AAAS.

Hodson, D. (1992). In search of a meaningful relationship: an exploration of some issues relating to integration in science and science education. International Journal of Science Education 14(5): 541-562.
Kyle, W. C. (1995). Editorial: Scientific literacy: How Many Lost Generations Can We Afford. Journal of Research in Science Teaching 32 (9): 895-896.

Layton, D.; Jenkins, E. MacCill, S. y Davey, A. (1993) Inarticulate Science? (Nafferton: Studies in Education).

Matthews, M. R. (1994). Science Teaching. London: Routledge.

Rutherford, F. J. y Ahlgren, A. (1990). Science for All American. Nueva York: Oxford University Press.

Shen, B. S. P. (1975). Science literacy: The public need. The Sciences, EneroFebrero: 27-29.

Wyne, W. (1995). Public Understanding of Science pp. 361-391. En Jasanoff, S. et ál. Handbook of Science and Technology Studies. Sage: Thousand Oaks. 